\title{
Problemas bioéticos na prática interequipes em uma unidade de Atenção Primária à Saúde no Brasil*
}

\author{
Juliana Marina - Carlos Dimas Martins Ribeirob
}

\begin{abstract}
Resumo: o objetivo deste trabalho é analisar a origem e os problemas bioéticos que emergem no processo de trabalho entre equipes em uma unidade de Atenção Primária à Saúde no Brasil. Esta investigação qualitativa conta com três etapas de operacionalização: etnografia, entrevista e grupo focal. O principal problema bioético encontrado, que compromete a produção do cuidado nesse nível de atenção, é a falta de solidariedade entre os profissionais das equipes e destes com os pacientes que não pertencem ao setor do território sob a sua responsabilidade. As razões desse problema bioético estão associadas à cobrança da gestão municipal para o incremento da produção e o alcance de metas, à falta de valorização dos trabalhadores das equipes e dos esforços empreendidos por eles no trabalho por parte da gestão e à estima assimétrica. Nesse sentido, a Bioética, no contexto da saúde pública, volta-se para a compreensão e discussão dos problemas vivenciados a fim de estabelecer um quadro de consciência moral e agir ético. Em determinados momentos, para a efetividade de uma equipe, é necessário o aporte solidário das outras, concretizado pelo reconhecimento de pertença a essa produção.
\end{abstract}

Palavras-chave: serviço de Saúde; relações entre grupos; bioética; ética

Recibido: 13 de marzo de 2019 Aceptado: 25 de marzo de 2020

Disponible en línea: 15 de septiembre de 2020.

Cómo citar: Marin J, Ribeiro CDM. Problemas bioéticos na prática interequipes em uma unidade de Atenção Primária à Saúde no Brasil. Rev. latinoam. bioet [Internet]. 15 de septiembre de 2020; 20(1). Disponible en: https://doi.org/10.18359/rlbi.3991

* Artigo de pesquisa resultado de tese de doutorado apresentada ao Programa de Pós-Graduação em Bioética, Ética Aplicada e Saúde Coletiva da Universidade Federal Fluminense, Brasil.

a Doutora em Bioética, Ética Aplicada e Saúde Coletica. Universidade Federal Fluminense, Niterói, Brasil. E-mail: jubsmarin@yahoo.com.br ORCID •

b Doutor em Saúde Coletiva. Universidade Federal Fluminense, Niterói, Brasil. E-mail: dimasmribeiro@gmail.com ORCID ○ 


\title{
Bioethical problems in the inter-team practice in a Primary Healthcare Unit in Brazil
}

\begin{abstract}
The objective of this work is to analyze the origin and the bioethical problems arising in the work process amongst teams in a Primary Health Care unit in Brazil. This qualitative research has three stages of operationalization: ethnography, interview, and focus group. The main bioethical problem found, which compromises the production of care at this level, is the lack of solidarity amongst the professionals in the teams and with the patients who do not belong to the sector of the territory under their responsibility. The reasons for this bioethical problem are associated with municipal management collection to increase production and the achievement of goals, the little appreciation for the team workers and their efforts at the job from the management and an asymmetric esteem. In this sense, bioethics in the context of public health becomes understanding and discussing the problems experienced to establish a framework of moral conscience and ethical action. At certain moments, a solidarity contribution from others, materialized in the recognition of being part of that production, is necessary for the effectiveness of a team.
\end{abstract}

Keywords: health service; group relationships; bioethics; ethics

\section{Problemas bioéticos en la práctica interequipos en una unidad de Atención Primaria a la Salud en Brasil}

Resumen: El objetivo de este trabajo es analizar el origen y los problemas bioéticos que emergen en el proceso de trabajo entre equipos en una unidad de Atención Primaria a la Salud en Brasil. Esta investigación cualitativa cuenta con tres etapas de operacionalización: etnografía, entrevista y grupo focal. El principal problema bioético encontrado, que compromete la producción del cuidado en ese nivel de atención, es la falta de solidaridad entre los profesionales de los equipos y de esos hacia los pacientes que no pertenecen al sector del territorio bajo su responsabilidad. Las razones de este problema bioético están asociadas al cobro de la gestión municipal para el incremento de la producción y el alcance de metas, a la falta de valoración de los trabajadores de los equipos y de los esfuerzos emprendidos por ellos en el trabajo por parte de la gestión y la estima asimétrica. En este sentido, la bioética en el contexto de la salud pública se convierte en comprender y discutir los problemas experimentados para establecer un marco de conciencia moral y acción ética. En determinados momentos, para la efectividad de un equipo es necesario el aporte solidario de los otros, concretado por el reconocimiento de pertenencia a esa producción.

Palabras clave: servicio de Salud; relaciones entre grupos; bioética; ética 


\section{Introdução}

No contexto do sistema público de saúde brasileiro, a proposta da Atenção Primária à Saúde (APS) se alicerça nos princípios da universalidade, equidade e integralidade da atenção, bem como do vínculo e acesso a esta, além da responsabilização, humanização e continuidade do cuidado.

A Estratégia Saúde da Família (ESF), modelo de aps no Brasil, surgiu em 1994 como uma proposta nacional para a oferta de ações de promoção, proteção e recuperação da saúde centradas no usuário e operacionalizadas por uma equipe multiprofissional, composta de um médico, um enfermeiro, um auxiliar ou técnico de enfermagem e seis agentes comunitários de saúde. A partir de 2000, o Ministério da Saúde do Brasil passou a incentivar a inclusão de um cirurgião-dentista e de um auxiliar e/ou técnico em saúde bucal na equipe, a fim de procurar garantir uma atenção integral em saúde.

Desde sua concepção, a esf tem o propósito de ser o contato preferencial dos usuários e a principal porta de entrada no Sistema Único de Saúde (sus). Além disso, de garantir a resolutividade para a maioria dos problemas de saúde, ocupando a posição de centro coordenador da rede de atenção, com a responsabilidade tanto pela circulação do usuário no sistema quanto pelo seu acompanhamento em qualquer nível de complexidade.

A organização do processo de trabalho de uma equipe é estabelecida a partir de um território geográfico definido, constituído, em média, por três mil pessoas, considerando as suas características e as necessidades da população a ele adscrita. Assim, proporcional ao tamanho do território populacional, é o número de equipes inseridas em uma unidade, cada uma responsável por um setor ou área geográfica adscrita a esse território populacional.

No trabalho em equipe, a divisão técnica por categoria profissional, que delimita a atribuição de cada membro da equipe, gera "expectativas em relação ao que se espera do desempenho uns dos outros, entre os trabalhadores [da equipe], e destes em relação aos usuários" (1, p. 21). Em correspondência, acreditamos que o trabalho interequipes também produz expectativas quanto a outra equipe, bem como do que os usuários esperam dessa conjugação. Tais expectativas são induzidas, nesse caso, pela existência da divisão técnica de equipe e pela área de abrangência geográfica, que define explicitamente o território populacional de atuação de cada equipe.

Ao mesmo tempo, com a inserção de múltiplas equipes, além das expectativas, amplia-se o número de profissionais com os mesmos saberes técnicos, mesmas funções práticas e com um modo próprio de agir no processo de trabalho, estruturando-se redes "a partir de determinado território de saberes, práticas, semiótico e subjetivo", o que diversifica o processo de trabalho no interior da unidade de saúde, "onde instituído e instituinte estão presentes, significando processos de permanente disputa" (2, p. 236).

Nesse sentido, as práticas de produção do cuidado em saúde, com frequência, apresentam-se centradas na execução de tarefas, e não no paciente, em ações curativas e com baixo grau de articulação entre os profissionais. Esse cenário tem configurado um ambiente de trabalho marcado por divergências de princípios, "incertezas sobre as tomadas de decisões e enfrentamentos na relação com os outros" (3, p. 228). Nessa conjuntura de deliberações e modos de agir nas relações humanas, insere-se a bioética (4), tendo como referenciais a dignidade humana, a responsabilidade, a solidariedade, entre outros (5).

$\mathrm{Na}$ dado que existe um conjunto de princípios que devem caracterizar o processo de trabalho para a produção do cuidado - como a responsabilidade pelo paciente e pelo trabalho, o compromisso, a integralidade, o acolhimento e a escuta que são, em grande medida, ideários bioéticos -, tudo que dificulta ou impede a produção de cuidado com essas características é um problema bioético (6).

Por mais que os profissionais, como agentes morais, tenham consciência do objetivo do trabalho na os modos de agir entre eles e com o paciente são influenciados por razões individuais internas ou externas, que podem dificultar a operacionalização do trabalho e prejudicar a produção do cuidado de acordo com os ideários bioéticos supracitados. 
A falta de companheirismo e colaboração, caracterizada pela dificuldade de comunicação, pela presença de maledicência e pelo baixo grau de interação entre as categorias profissionais, tem sido apontada como problema bioético entre equipes (7). Nesse sentido, a bioética, no contexto da saúde pública, deve buscar a compreensão e discussão dos problemas experenciados e, assim, tentar estabelecer um quadro de consciência moral e ação ética para a mudança das práticas (8).

Com essa perspectiva, o objetivo desta pesquisa foi analisar os problemas bioéticos que emergem no processo de trabalho entre equipes e as razões para sua emersão, em uma unidade de aps no município de Niterói, estado do Rio de Janeiro, Brasil.

\section{Materiais e métodos}

Para a escolha da equipe participante, considerou-se aquela composta por médico, enfermeiro, agentes comunitários de saúde (ACS), cirurgião-dentista, auxiliar de saúde bucal (ASB) e técnico de enfermagem, e que estivesse entre as equipes mais antigas, com a mesma formação, do município de Niterói, pois se presumiu que o acúmulo de experiências pudesse aumentar a possibilidade de experiências conflituosas. Considerou-se, também, a existência de, pelo menos, outra equipe inserida no módulo. A equipe incluída neste estudo é constituída por um médico, um enfermeiro, dois acs, um cirurgião-dentista, um asb e um técnico de enfermagem. Além disso, foi incluído um usuário que pertence ao setor sob a responsabilidade da equipe, a partir da indicação da maioria dos profissionais, quando questionados sobre qual seria o paciente que apresentava mais problemas, de maneira geral, na sua relação com a equipe. Os oito participantes aceitaram a participar desta pesquisa e assinaram o Termo de Consentimento Livre e Esclarecido.

Com o objetivo de realizar um estudo qualitativo em profundidade, a pesquisa foi operacionalizada em três etapas sequenciais: etnografia, entrevistas e grupo focal.

A escolha pela etnografia se justifica pela tentativa de verificar in loco o convívio diário da equipe estudada com as outras equipes e pacientes, especialmente com o participante, o que foi possível em dois momentos distintos na unidade.
A segunda etapa da investigação compreendeu uma entrevista com o paciente e com cada profissional da equipe com o auxílio de um roteiro semiestruturado. As entrevistas, que totalizaram um tempo de aproximadamente oito horas e meia, foram realizadas na própria unidade de saúde, com os profissionais, e na residência do paciente, para verificar suas percepções sobre as equipes.

Após as entrevistas, realizou-se um grupo focal com os profissionais - exceto o dentista que foi transferido para a assistência de outro território -, o que permitiu um estudo dos posicionamentos em relação aos temas levantados nas entrevistas.

Para a fidedignidade dos registros, as entrevistas foram gravadas, e o grupo focal, filmado, com a autorização dos participantes. Os relatos foram transcritos literalmente pela pesquisadora.

Para minimizar o risco de identificação dos profissionais participantes e dos citados, para cada profissional da unidade, foi utilizado um número arábico de identificação de forma sequencial e aleatória em algarismos arábicos de 1 a 24 e, para cada equipe, uma letra do alfabeto grego: $\alpha, \beta, \gamma$ e $\delta$, sendo que $\alpha$ foi o código para a equipe participante da pesquisa e os códigos $\beta$, $\gamma$ e $\delta$ se referiram às outras equipes citadas no estudo. Ainda, para reduzir o risco de identificação, não foram informadas as profissões. Optou-se, nesse caso, por atribuir algarismos romanos em dois grupos de acordo com o nível de escolaridade: I para profissionais de nível superior (enfermeiro, médico e dentista) e II para profissionais de nível técnico, médio ou fundamental (ACS, ASB e técnico de enfermagem). Assim, os profissionais foram identificados de acordo com o exemplo: $1 \alpha$ I - profissional 1 , da equipe a e de nível superior. 9 $\beta$ II - profissional 9, da equipe $\beta$ e de nível técnico, médio ou fundamental.

Para a análise dos dados, buscou-se descobrir os "núcleos de sentido" das informações, sua frequência pela exploração das opiniões e do comportamento dos participantes e seus significados pela inferência (9, p. 316).

Este trabalho foi aprovado pelo Comitê de Ética em Pesquisa do Hospital Universitário Antonio Pedro da Universidade Federal Fluminense, no município de Niterói, Brasil, com o parecer de 
número 1.388.580, no ano de 2016; está de acordo com a Resolução 466/2012 do Conselho Nacional de Saúde, que considera o respeito pela dignidade humana e pela proteção devida aos participantes das pesquisas científicas, conforme documentos internacionais, em especial a Declaração de Helsinque.

\section{Resultados e discussão}

\section{Problemas bioéticos interequipes}

A unidade de saúde é composta por quatro equipes que totalizam 24 profissionais. Cada equipe é constituída por um enfermeiro, um técnico de enfermagem, dois ACs, um médico, um dentista e um ASB, dos quais os dois últimos atuam em duas equipes. Cada equipe é respo nsável por um setor ou área com aproximadamente 2.500 pessoas e deve, prioritariamente, atender o paciente do seu setor.

Os quatro médicos, bem como os dois dentistas, desempenham ações na unidade e no território. Os quatro enfermeiros, além destas, desempenham ações gerenciais, e um deles se destaca como líder não só de sua equipe, mas de todas as outras. Cada asb acompanha um dentista em suas ações e os oito acs desenvolvem ações principalmente no território, além de se revezarem na unidade para receber os pacientes em períodos predeterminados, na primeira hora de funcionamento da unidade, no período da manhã e da tarde. Após esse horário, os quatro técnicos de enfermagem, que realizam ações que são de sua competência técnica, na clínica e no território, recebem o paciente na unidade.

A oferta de ações, interpostas pelo acolhimento e pela responsabilização, requer um envolvimento sinérgico de todos os profissionais para o cuidado do paciente. Essa perspectiva deve envolver não apenas o trabalho em equipe, mas também o interequipes.

O que é dito em toda reunião [interequipes]:"um [profissional] ajuda o outro!" Se o paciente é do setor [da equipe] $\alpha$, mas quem tá ali na frente é [profissional da equipe], $\beta, \gamma$ ou $\delta$, você vai fazer aquilo [ajudar o profissional da outra equipe]. Você não vai deixar o paciente ali porque a pessoa [profissional da equipe do paciente] não tá ali [...]: "ah não, você é do setor [da equipe] $\alpha$, você volta amanhã". não! Tem que ser feito, o paciente tá ali, ele tem que ser cuidado ( 5 aII).

Não tem necessidade de o paciente ficar esperando uma hora pra poder fazer uma vacina, verificar uma pressão né, então teoricamente, todo mundo pode atender todos os pacientes (7aI).

Nesse sentido, a perspectiva de trabalho interequipes implica corresponsabilidade de todos os profissionais, que se associa ao reconhecimento quanto ao seu pertencimento e relevância em uma prática laboral que tem por objetivo o cuidado do usuário.

Para Ricoeur (10), há três esferas de reconhecimento: o reconhecimento enquanto identificação, no sentido de estabelecer uma relação de identidade com a equipe; o reconhecimento de si, concebido pela identificação de suas próprias capacidades, e, por fim, o reconhecimento mútuo, em que as capacidades individuais são oferecidas pelos agentes, uns aos outros, em seu agir, de forma recíproca.

Esse reconhecimento polissêmico "exige uma dialética de autocentramento e descentramento que configura os perfis de uma moral solidária para além do egoísmo" (11, p. 291), o que envolve pensar em pessoas diferentes de nós mesmos, como incluídas na denominação "nós" (12).

Trabalhar em conjunto envolve colaboração, mas pensar a colaboração pelo olhar da interdisciplinaridade é reconhecer as diferenças que tornam o trabalho mais resolutivo (13), é pensar a solidariedade que se associa ao reconhecimento de que os indivíduos dependem uns dos outros (14).

A solidariedade referida ao processo de trabalho na ESF se constitui em função da produção do cuidado ao usuário, o que envolve pensar nela entre os profissionais e deles com os pacientes em benefício dessa produção, pelo reconhecimento das diferenças e da interdependência. A solidariedade como princípio bioético pressupõe a função de orientar as condutas dos profissionais de forma colaborativa e interventiva (15), comprometidas, portanto, com as dimensões morais do trabalho e do cuidado em saúde.

Relações solidárias também envolvem a concepção de suporte compartilhado entre os profissionais e a responsabilidade desses pelos pacientes (16). 
Para a produção do cuidado, os profissionais reafirmam a necessidade de estender sua atuação para além de sua equipe, pela composição de uma rede conectiva e solidária interequipes, na qual as responsabilidades por essa produção são compartilhadas.

É uma equipe no geral, independente do setor é uma equipe, nós somos uma equipe, então se eu não atender aquele paciente porque ele não é do meu setor, eu estou prejudicando o paciente ( $5 \alpha \mathrm{II})$.

A ausência de solidariedade entre os profissionais das equipes acaba por prejudicar, indiretamente, a produção do cuidado, o que se concretiza como um problema bioético. É certo que a capacidade resolutiva de uma equipe é maior quando se trata do paciente morador da área sob sua responsabilidade, por acompanhá-lo, por conhecer a realidade vivida por ele e suas necessidades de saúde. Entretanto, quando um profissional de uma equipe não está disponível para o atendimento, um profissional de outra equipe que tenha sido abordado pelo paciente deveria, no mínimo, acolhê-lo. Mesmo que a demanda não possa ser resolvida, deve-se prover algum tipo de encaminhamento para o usuário, o que nem sempre acontece.

"Ah, o paciente é seu”, tem essa separação [entre as equipes]. Não! O paciente é da unidade! [...] você vê alguém mais individualista: “ah, esse paciente não é meu, despacha, não quero nem saber.” (2aII)

Tem uma guerra, como se fosse uma guerra: "fulano [profissional] não está, não vou atender o paciente dele, não vou atender, não é minha paciente não! Espera fulano"! Às vezes, com receita pra pegar [medicamento] na farmácia, não precisa esperar a sua técnica [do setor do paciente] pra poder pegar um remédio pro paciente! [...] Paciente entrou [na unidade], é de todo o mundo! A gente sabe que o técnico, o enfermeiro, o acs do setor consegue resolver melhor, mas se eu posso verificar o peso, uma pa [pressão arterial], se eu posso pegar um remédio na farmácia, por que eu não vou fazer? Quando essa guerra vai acabar? (5aII)

Sobre o argumento "se eu posso", 5aii referese à capacidade técnica e à disponibilidade do profissional. A guerra que se estabelece na unidade; envolve, por um lado, aqueles profissionais que são resistentes ao atendimento de pacientes que são acompanhados por outra equipe e, por outro, aqueles que entendem que a solidariedade deve fundamentar o trabalho interequipes. No centro, está o mais prejudicado por essa guerra: o paciente com sua demanda. Quando uma equipe afirma que seus membros não são responsáveis por atender o paciente de outra equipe, a produção do cuidado é deslocada em vez de compartilhada (17).

Essa guerra proclamada atende interesses individuais em detrimento ao coletivo, sendo oposta à solidariedade requerida para a produção do cuidado. O indivíduo se pauta na divisão populacional que existe entre as equipes, e não no fato de ser um profissional da saúde e, mais, que trabalha na perspectiva da ESF.

É necessária, em determinadas situações, uma identidade coletiva que enquadre os indivíduos como profissionais de uma unidade da ESF e que ofusque a "multiplicidade das pertenças" às equipes, a fim de constituir um trabalho interequipes organizado em torno de um objetivo preponderante $(18$, p. 125).

Diante disso, é expressa também uma ausência de organização do processo de trabalho interequipes. Apesar de existir um esforço gerencial de implementação, não há como realizá-la se não houver solidariedade entre os profissionais. Portanto, assim como reunir as pessoas não torna uma equipe eficaz, reunir equipes não proporciona necessariamente um trabalho interequipes eficaz (17).

Além de a ausência de solidariedade nas relações interequipes refletir indiretamente na produção do cuidado, a relação do profissional com o paciente que não é do seu setor interfere negativamente nessa produção. Como supracitado, o profissional deveria, no mínimo, acolher o paciente, uma vez que isso significa ouvir as demandas, compreendê-las e se solidarizar com ele (19).

$O$ pessoal fala de acolhimento, mas tem gente que não sabe acolher [...] é um dever! Isso aqui é uma unidade de saúde! Nós temos que tratar bem todo o mundo que chega aqui [...] poucos [usuários] que falam bem dessa unidade de saúde, por conta das pessoas [profissionais], por falta de tratamento no acolhimento ( $3 \alpha \mathrm{II})$.

Acho que a maioria dos atritos que acontecem entre o paciente/usuário e funcionário é a questão do acolhimento (7aI). 
O acolhimento, bem como apresentado por Brehmer e Verdi (20, p. 3577), é implementado "com inúmeros reveses [...] com implicações éticas expressivas, como o descaso com a qualidade da atenção, a limitação do acesso e a negação do direito". Em outros casos, mesmo as demandas mais simples que poderiam ser resolvidas de imediato, não são atendidas por falta de solidariedade.

Exemplo: eu quero um remédio, às vezes você está com uma pressa, está precisando daquele remédio [e o profissional diz]: "não, você tem que esperar porque fulano [profissional] do seu setor está ocupado". Aí você tem que esperar, mas você está vendo [para] outras pessoas sendo entregue o remédio [...] por que aquela mesma pessoa [profissional] não quer [entregar para mim]? Mas não é do meu setor, por que ela não pode pegar e me entregar o remédio para me adiantar? Aí eu fico meia chateada disso (Paciente).

Paciente que entra [na unidade]: "ah tem tal remédio?" Eu já vi técnica falando que não tem pra não ter que ir lá pegar (1aI).

É inaceitável que o processo de trabalho interequipes se estabeleça nesses termos. Nesses casos, não há solidariedade do profissional pelo paciente e sequer discernimento da situação. Portanto, é necessário que se coloque em análise o modo de operar para a percepção das fragilidades e potenciais para mudanças, pois o cuidado é um objetivo comum e se concretiza no modo de agir do profissional ante o paciente e na interação entre os profissionais.

É importante pontuar que o cuidado se apoia também em outras dimensões como a disponibilidade de serviços e insumos, de mecanismos de regulação, que, apesar de dimensões fundamentais para o alcance da integralidade, não foram objetos deste estudo.

A solidariedade, dentro da qual a colaboração está subsumida, também envolve a tolerância para com as particularidades do outro (21). Nesse sentido, a falta dela entre os profissionais pode resultar em outro problema bioético, que lesa os aspectos morais do trabalho, quando a intolerância para com uma particularidade de um profissional está velada e é insinuada por meio de fofoca ${ }^{1}$.
Eu saí, eu fui pra sala de escovação, que era lá atrás [na unidade], aí não tinha ninguém aqui pra avisar [que eu ia pra sala de escovação], aí peguei meus livros, fui fazer umas coisinhas, aí depois as meninas [profissionais]: "você estava aonde?" [2aII respondeu]: "eu estava na sala de escovação", [e as meninas responderam]: "ah porque $13 \beta$ II falou que você estava dando um ' $s$ ". Dando um "s" é dando uma volta, ido pra casa, qualquer coisa assim (2aII).

Todo dia eles me contam, fofoca: "fulano não trabalhou direito, fulano não fez isso direito". Na quarta-feira, meu filho passou mal, aí eu não vim [pra unidade] [...] aí no outro dia, quando eu cheguei de manhã, a 238II: "olha, ontem a $6 \alpha$ II não fez nada, não trabalhou, não ajudou, ficou a toa". [Eu disse:] "então tá, eu vou conversar com ela", aí passou o dia, o $14 \beta \mathrm{I}$ veio conversar comigo: "pô, a 6aII ajudou a beça ontem", aí eu falei: "mas a $23 \delta I I$ falou que ontem $6 \alpha$ II não tinha feito nada” (7aI).

Sempre rola uma fofoquinha. Aí outro dia que eu fui pra rua [campo] com as meninas [ACS], aí a 9 $9 \mathrm{II}:$ "ah já foi pra rua, correu porque não quer ficar aqui atendendo", umas coisas assim, sabe? [...] eu ficava bem chateada $(1 \alpha \mathrm{I})$.

A intolerância pelas diferenças leva à defecção da comunicação, pois os profissionais "não falam o que gostariam, nem ouvem as outras [pessoas], só captam o que reforça sua imagem das outras e da situação", por consequência, o convívio pode tornar-se conflitivo (23, p. 35).

A mudança de paradigmas estruturados nas relações interpessoais é um desafio que implica a transformação das práticas (24). Pensar a sinergia das diversas competências em busca da solidariedade exige um "'luto' da onipotência de cada profissional” $(25$, p. 118$)$, pois, para existir solidariedade nas relações, os indivíduos presumem, enquanto membros de uma comunidade moral, uma igualdade de tratamento, a partir do fundamento de que cada profissional considere os outros como "um dos nossos" (26, p. 42).

Fofocar é falar o que se vê ou ouve de uma pessoa ausente, o que esta fez ou se imagina o que ela tenha feito e os motivos para isso; nesse caso, "a fofoca é uma hipótese baseada em dados mais do que deficientes” e, por vezes, falsos (22), que provoca sofrimento nos trabalhadores e pode engendrar diversos problemas e conflitos bioéticos. 
Apesar de os profissionais reconhecerem a solidariedade como um princípio para a produção do cuidado, no processo de trabalho interequipes, ela não ocorre em todas as relações, o que se constitui como o principal problema bioético interequipes expresso pelos participantes desta pesquisa. Também foram identificados outros problemas bioéticos desencadeados pela falta de solidariedade, como a satisfação de interesses individuais em detrimento ao coletivo, a ausência de organização do processo de trabalho interequipes, o descaso com o acolhimento e a intolerância. Dessa maneira, embora saibam o que é moralmente correto fazer, outras razões acabam sendo mais fortes e influenciam o modo de agir dos profissionais (26).

\section{Causas dos problemas bioéticos no processo de trabalho interequipes}

As razões para a emersão dos problemas bioéticos no processo de trabalho interequipes são: a cobrança da gestão para o alcance de metas, a desvalorização dos profissionais e dos esforços empreendidos por eles no trabalho e as relações de estima.

A cobrança da gestão para o alcance de metas se volta para a operacionalização de um processo de trabalho centrado na produção de procedimentos, e não na produção de saúde, que passa a ser o objetivo final do trabalho, o que contraria a perspectiva do que é recomendado na própria política de saúde (1).

Esse cenário propende para a redução do envolvimento da equipe, com atividades relacionadas aos membros de outra equipe, o que inclui aquelas mais diretamente ligadas aos usuários (27).

A gente ficava com uma pressão muito grande: "a gente tem que fazer, a gente tem que fazer"; [e a gestão]: “vocês não estão fazendo bem, vocês não estão fazendo bem [...] vocês não estão agindo corretamente, isso não tá bem, vocês não estão atingindo uma meta!" Mas o que que a gente pode fazer pra isso ser alcançado? E não simplesmente: "não, não, não, não tá bem, não tá bem" (7aI).

No sistema público de saúde, apesar de ser requisitada cada vez mais a participação do trabalhador, há uma limitação de sua atuação, devido ao "pouco conhecimento e pouca governabilidade das equipes em relação à definição de metas e indicadores (locais) que norteiam seu próprio trabalho" $(28$, p. 74$)$. A pouca governabilidade das equipes pode inclusive fomentar um conflito entre os profissionais, como apresentado em diálogo extraído do grupo focal:

- De repente alguém lá em cima que pede pra fazer uma coisa absurda, surreal, a gente faz. (4aI)

- Mas isso gera discórdia entre vocês? (Pesquisadora)

- Às vezes sim, ela tá sabendo que tem que fazer alguma coisa, aí eu falo: “7aI, é absurdo fazer isso", aí acabo ficando irritada porque acho um absurdo, a gente começa a discutir, discutir $(4 \alpha \mathrm{I})$.

Além disso, a cobrança por metas se estabelece sem a aclaração necessária para alcançá-las, o que torna essa exigência incoerente para os trabalhadores, desorienta-os e desestimula-os, pois o que é feito por eles parece, no ponto de vista deles, nunca ser suficiente. Isso revela uma desvalorização dos profissionais e dos esforços empreendidos por eles no trabalho.

Eu gosto de trabalhar aqui, gosto mesmo, gosto e fico muito chateada às vezes quando não tem um retorno [...] da gestão, a parte da gestão de feedback [...] eu não vejo isso na gestão de cima. Nem um parabéns sequer, pra dizer assim: "oh, parabéns, fizeram uma ação legal." (7aI)

No entanto, "valorizar é avançar na perspectiva de entender os trabalhadores como sujeitos de seu saber, seu fazer, seu trabalho", de maneira que sua inserção e atuação proporcionem "à ampliação de sua proposição no âmbito coletivo, constituindo-se como equipes" (28, p. 149).

A gestão só sabe impor, eles não sabem ouvir, eles até ouvem, mas acaba dando razão sempre pro outro lado, a gente aqui nunca tem razão [...] quase sempre não tem razão pra eles, sempre o paciente. Igual mercado, comércio: o freguês tem sempre razão, então pra eles é assim (3aII).

De acordo com Campos (27, p. 395), "um sistema de poder altamente verticalizado, com tomada centralizada de decisões, tende a estimular descompromisso e alienação" nos trabalhadores, o que dificulta o estabelecimento de relações solidárias.

Esse processo de tensão que há entre trabalhadores e gestores pode provocar a submissão dos profissionais ou a solidariedade entre eles para a 
resistência coletiva a essa dominação que a gestão imprimi (29). Contudo, apesar de ser um fato que os afeta, os questionamentos dos profissionais, por apreensão, não se concretizam em uma resistência nem individual, nem coletiva.

Por que que você tem que ser bonzinho, ser o técnico, o enfermeiro bonzinho, tem que segurar tudo? Tem horas que você vai explodir! Você é ser humano! Corre sangue na veia! Então isso daí tem que ser respeitado [...] a gente fala muito do usuário, e o profissional? (6aII).

Muito embora a contratação seja feita com base no regime da Consolidação das Leis do Trabalho, os profissionais temem perder o trabalho e, por isso, submetem-se a essas imposições, já que alguma resistência pode ser motivo de demissão, pela facilidade de contratação de profissionais no mercado, com exceção do médico.

Assim, a cobrança por metas faz com que o profissional perca a essência do cuidar, na perspectiva de que a quantidade de ações produzidas é mais valorizada que a qualidade delas. Esse quadro tensiona o individualismo, o que tende a enfraquecer os vínculos de solidariedade (30) e compromete o trabalho coletivo bem como a produção do cuidado.

Da mesma forma, se não houver valorização do profissional e do seu empenho, por qual razão ele deveria empreender um esforço para estender suas atribuições e contribuir com outra equipe ou atender um paciente que não seja do seu setor?

Outro aspecto que influencia a emersão dos problemas bioéticos no processo de trabalho interequipes é a estima assimétrica entre os profissionais, pois a solidariedade está ligada ao pressuposto de relações sociais de estima simétrica entre sujeitos individualizados (21). Esta, de acordo com Honneth (21, p. 210), significa reconhecer, de forma recíproca, "as capacidades e as propriedades do respectivo outro [...] como significativas para a práxis comum".

Entretanto, as capacidades e as propriedades de todos os outros nem sempre são reconhecidas como significativas para a produção do cuidado, o que acarreta uma experiência de desrespeito, seguida de reações emocionais como vergonha ou ira - que caracteriza a estima assimétrica -, desencadeando conflitos bioéticos (21), que levam a um círculo vicioso de insolidariedade, como pode ser observado nos depoimentos a seguir.

[Exemplo] se eu posso levar esse copo com água aqui porque alguém esqueceu, eu não vou levar porque é seu o copo, eu vou deixar aí, mas pode encher de formiga porque está com café. Não! Vou deixar aí, que se dane, e é uma coisa simples, uma coisa boba, mas que faz diferença quando você trabalha com pessoas ( $2 \alpha I I)$.

Tem a pessoa que fica botando você lá no chão! Quem vai querer ajudar aquela pessoa? ( $4 \alpha \mathrm{I})$.

Portanto, a desvalorização dos profissionais e dos esforços empreendidos por eles no trabalho, a cobrança por incremento da produção no trabalho e as relações de estima assimétrica são as razões da falta de solidariedade entre os profissionais e entre estes e os pacientes que não pertencem ao seu setor.

Bem como apresentado por outros autores (31), relações solidárias foram marcantes especialmente entre os acs e entre estes e os pacientes, pela própria dimensão cuidadora utilizada no seu processo de trabalho, que não está isenta em outros profissionais, mas está potencializada nos acs por serem agentes de saúde da comunidade onde residem.

\section{Considerações finais}

No trabalho interequipes, a ausência de solidariedade dos profissionais foi o problema bioético principal encontrado nesta pesquisa. Também foram identificados outros problemas bioéticos, como a satisfação de interesses individuais em detrimento ao coletivo, a ausência de organização do processo de trabalho interequipes, o descaso com o acolhimento e a intolerância.

As causas dos problemas bioéticos no processo de trabalho interequipes são, neste estudo, a cobrança da gestão por incremento da produção, a desvalorização dos profissionais e dos esforços empreendidos por eles no trabalho por parte da gestão e as relações de estima assimétrica.

O trabalho interequipes deve ser uma ferramenta indutora de mudança no processo de produção do cuidado. Nesse sentido, para o sucesso de uma equipe, é necessário o aporte das outras, ou seja, a efetividade da produção do cuidado requer também a constituição de uma rede conectiva entre as equipes. Nesses termos, a responsabilidade 
por um paciente deve ser compartilhada entre as equipes. Para que isso se concretize, é fundamental haver solidariedade dos profissionais, que deve ser incluída na prática clínica da esf como imperativo bioético para a concretização do cuidado. Portanto, os profissionais, as equipes e a gestão devem assimilar que a produção do cuidado envolve a todos simultaneamente, pelo reconhecimento de si e do outro como parte essencial do processo.

Quando o usuário não obtém uma resposta resolutiva à sua demanda, há o comprometimento da dimensão moral do trabalho e a emersão de problemas bioéticos. Em determinadas situações, o profissional não antecipa as implicações bioéticas do seu modo de agir e, por vezes, não as percebe. Assim, é importante que tanto reflexões bioéticas quanto as suas respectivas ações futuras sejam incorporadas nas práticas da ESF e da gestão.

Constitui-se como uma limitação deste estudo a possibilidade da existência de outros problemas e conflitos bioéticos, assim como os motivos para sua emersão, que não foram identificados nesta pesquisa.

Na literatura, há um grande enfoque no trabalho em equipe; assim, são necessários mais estudos que evidenciem a forma como se estabelecem as relações interequipes. Os problemas bioéticos que emergem desse processo de trabalho e as razões para o seu desenvolvimento podem ser característicos ou semelhantes aos que surgem no processo de trabalho de uma equipe, e, da mesma forma, podem comprometer os propósitos da ESF.

\section{Referências bibliográficas}

1. Matumoto S, Fortuna CM, Mishima SM, Pereira MJB, Domingos NAM. Supervisão de equipes no Programa de Saúde da Família: reflexões acerca do desafio da produção de cuidados. Interface, Comun., Saúde, Educ. (Online). 2005 [acesso em out. 2016];9(16):9-24. DoI: https://doi.org/10.1590/S1414-32832005000100002

2. Franco TB. As redes da micropolítica do processo de trabalho em saúde. Em: Merhy EE, Franco TB, organizadores. Trabalho, produção do cuidado e subjetividade em saúde: textos Reunidos. São Paulo: Hucitec; 2013. pp. 226-42.

3. Montenegro LC, Rénno HMS, Caram CS, Brito MJM. Problemas éticos na prática de profissionais de saúde em um hospital escola. Av Enferm. 2016 [acesso em fev. 2018];34(3):226-35. DoI: https://doi.org/10.15446/ av.enferm.v34n 3.45590

4. Cortina A. Bioética para el siglo xxi: construyendo esperanza. Rev. iberoam. bioét. 2016 [acesso em fev. 2018];(1):1-12. DOI: https://doi.org/10.14422/rib.i01. y2016.001

5. Alarcón RG, Montagner MA. Epistemología de la bioética: extensión a partir de la perspectiva latino-americana. Rev. Latinoam. Bioet. 2017 [acesso em dez. 2018];17(2):107-22. DoI: https://doi.org/10.18359/ rlbi.2256

6. Marin J, Ribeiro CDM. Problemas e conflitos bioéticos da prática em equipe da Estratégia Saúde da Família. Rev. Bioét. 2018[acesso em jan. 2019];26(2):291-301. DOI: https://doi.org/10.1590/1983-80422018262250

7. Valadão PAS, Lins L, Carvalho FM. Problemas bioéticos no cotidiano do trabalho de profissionais de equipes de saúde da família. Trab. Educ. Saúde (Online). 2017; [acesso em dez. 2018];15(3):725-44. DoI: https:// doi.org/10.1590/1981-7746-sol00080

8. Mendieta-Izquierdo G, Cuevas-Silva JM. Bioética de la salud pública. Rev. Latinoam. Bioet. 2017[acesso em dez. 2018];17(33-2):1-5. DoI: https://doi.org/10.18359/ rlbi.2929

9. Minayo MCS. O desafio do conhecimento: pesquisa qualitativa em saúde. São Paulo: Hucitec; 2010.

10. Ricoeur P. Percurso do reconhecimento. São Paulo: Edições Loyola; 2006.

11. Cortina A. Ética sem moral. São Paulo: Martins Fontes; 2010.

12. Rorty R. Contingency, irony, and solidarity. Cambridge: University Press; 1993.

13. Davies C. Getting health professionals to work together: There's more to collaboration than simply working side by side. bmj. 2000[acesso em jan. 2017];320:102122. DOI: https://doi.org/10.1136/bmj.320.7241.1021

14. Patrus R, Dantas DC, Shigaki HB. O produtivismo acadêmico e seus impactos na pós-graduação stricto sensu: uma ameaça à solidariedade entre pares? Cad. ebape.br. 2015[acesso em jan. 2017];13(1):1-18. DOI: https://doi.org/10.1590/1679-39518866

15. Selli L, Garrafa V, Meneghel SN. Bioética, solidariedade, voluntariado e saúde coletiva: notas para discussão. Rev. Bioét. 2005[acesso em out. 2016];13(1):53-64. Disponível em: http://revistabioetica.cfm.org.br/index. php/revista_bioetica/article/view/92/98

16. Laitinen A. From recognition to solidarity: universal respect, mutual support, and social unity. Em: Laiti- 
nen A, Pessi AB, editors. Solidarity: Theory and Practice. Lexington Books; 2014. pp. 126-154.

17. Ryan DP, Cott C, Robertson D. Conceptual Tools for Thinking about Inter-teamwork in Clinical Gerontology. Educ Gerontol. 1997[acesso em out. 2016];23(7):651669. DoI: https://doi.org/10.1080/0360127970230704

18. Boudon R, Besnard P, Cherkaoui M, Lécuyer BP. Dicionário de Sociologia. Lisboa: Publicações Dom Quixote; 1990.

19. Ayres RCV, Pereira SAOE, Ávila SMN, Valentim W. Acolhimento no PSF: humanização e solidariedade. Mundo Saúde (Online). 2006[acesso em nov. 2016];30(2):306-11. Disponível em: http://www.saocamilo-sp.br/pdf/mundo_saude/35/acolhimento_psf.pdf

20. Brehmer LCF, Verdi M. Acolhimento na Atenção Básica: reflexões éticas sobre a Atenção à Saúde dos usuários. Ciênc. Saúde Colet. (Online). 2010[acesso em out. 2016];15(Supl 3):3569-78. DoI: https://doi. org/10.1590/S1413-81232010000900032

21. Honneth A. Luta por reconhecimento: a gramática moral dos conflitos sociais. São Paulo: Ed. 34; 2009.

22. Gaiarsa JA. Tratado geral sobre a fofoca: uma análise da desconfiança humana. São Paulo: Ágora; 2015.

23. Moscovici F. Desenvolvimento interpessoal; treinamento em grupo. Rio de Janeiro: José Olympio; 2005.

24. Nascimento DDG, Oliveira MAC. Reflexões sobre as competências profissionais para o processo de trabalho nos Núcleos de Apoio à Saúde da Família. Mundo Saúde (Online). 2010[acesso em nov. 2016];34(1):92-6. DOI: https://doi.org/10.15343/0104-7809.201019296

25. Franco TB, Merhy EE. Programa de Saúde da Família (psf): contradições de um programa destinado à mudança do modelo tecnoassistencial. Em: Merhy EE, Magalhães Júnior HM, Rimoli J, Franco TB, Bueno WS, organizadores. O trabalho em saúde: olhando e experienciando o sus no cotidiano. São Paulo: Hucitec; 2003. pp. 55-124.

26. Habermas J. A inclusão do outro: estudos de teoria política. São Paulo: Loyola; 2002.

27. Campos GWS. Equipes de referência e apoio especializado matricial: um ensaio sobre a reorganização do trabalho em saúde. Ciênc. Saúde Colet. (Online). 1999[acesso em nov. 2016];4(2):393-403. DOI: https:// doi.org/10.1590/S1413-81231999000200013

28. Santos-Filho SB. Dando visibilidade à voz dos trabalhadores: possíveis pontos para uma pauta de valorização? Em: Santos-Filho SB, Barros MEB, organizadores. Trabalhador da saúde: muito prazer! Protagonismo dos trabalhadores na gestão do trabalho em saúde. Ijuí, RS: Editora Unijuí; 2007. pp. 251-265.
29. Ayala ALM, Oliveira WF. A divisão do trabalho no setor de saúde e a relação social de tensão entre trabalhadores e gestores. Trab. Educ. Saúde (Online). 2007[acesso em nov. 2016];5(2):251-70. DoI: https://doi. org/10.1590/S1981-77462007000200003

30. Abbagnano N. Dicionário de filosofia. São Paulo: Martins Fontes; 2007.

31. Ferreira VSC, Andrade CS, Franco TB, Merhy EE. Processo de trabalho do agente comunitário de saúde e a reestruturação produtiva. Cad. saúde pública (Online). 2009[acesso em out. 2016];25(4):898-906. DOI: https://doi.org/10.1590/S0102-311X2009000400021 